\title{
Visfatin Reduces Gap Junction Mediated Cell-to-Cell Communication in Proximal Tubule-Derived Epithelial Cells
}

\author{
Claire E. Hills Michael I. Kerr Mark J. Wall Paul E. Squires \\ School of Life Sciences, University of Warwick, Coventry, CV4 7AL, UK
}

\section{Key Words}

Visfatin - Gap Junctions - Proximal Tubule - Transforming Growth Factor Beta1 - Diabetic Nephropathy

\begin{abstract}
Background/Aims: In the current study we examined if the adipocytokine, visfatin, alters connexin-mediated intercellular communication in proximal tubule-derived epithelial cells. Methods: The effects of visfatin $(10-200 \mathrm{ng} / \mathrm{mL})$ on cell viability and cytotoxicity in HK2-cells were assessed by MTT, crystal violet and lactate dehydrogenase assays. Western blot analysis was used to confirm expression of Cx26, Cx40 and Cx43. The effect of visfatin (10-200 ng $/ \mathrm{mL})$ on TGF- $\beta 1$ secretion was confirmed by ELISA, and the effects of both TGF- $\beta 1(2-10 \mathrm{ng} / \mathrm{mL})$ and visfatin $(10-200 \mathrm{ng} / \mathrm{mL})$ on connexin expression were assessed by western blot. Functional intercellular communication was determined using transfer of Lucifer Yellow and pairedwhole cell patch clamp electrophysiology. Results: In low glucose (5mM), visfatin (10-200ng/ $\mathrm{mL}$ ) did not affect membrane integrity, cytotoxicity or cell viability at $48 \mathrm{hrs}$, but did evoke a concentration-dependent reduction in $\mathrm{C} \times 26$ and $\mathrm{C} \times 43$ expression. The expression of $\mathrm{C} \times 40$ was unaffected. At $48 \mathrm{hrs}$, visfatin $(10-200 \mathrm{ng} / \mathrm{mL})$ increased the secretion of TGF- $\beta 1$ and the visfatin-evoked changes in connexin expression were mimicked by exogenous application of the pro-fibrotic cytokine $(2-10 \mathrm{ng} / \mathrm{ml})$. Visfatin reduced dye transfer between coupled cells and decreased functional conductance, with levels falling by $63 \%$ as compared to control. Although input resistance was increased following visfatin treatment by $166 \%$, the change was not significant as compared to control. The effects of visfatin on Cx-expression and cellcoupling were blocked in the presence of a TGF- $\beta 1$ specific neutralizing antibody. Conclusions: The adipocytokine visfatin selectively evoked a non-toxic reduction in connexin expression in HK2-cells. The loss in gap-junction associated proteins was mirrored by a loss in functional conductance between coupled cells. Visfatin increased TGF- $\beta$ secretion and the pattern of change for connexins expression was mimicked by exogenous application of TGF- $\beta 1$. The effect of visfatin on Cx-expression and dye transfer were negated in the presence of a TGF- $\beta 1$ neutralising antibody. These data suggest that visfatin reduces connexin-mediated intercellular communication in proximal tubule-derived epithelial cells via a TGF- $\beta$ dependent pathway.
\end{abstract}




\section{Introduction}

Visfatin is an adipo-cytokine produced and secreted mainly by visceral adipose tissue. Alternatively known as the pre-B cell colony-enhancing factor, studies suggest that visfatin acts as an insulin-mimetic, capable of binding to the insulin receptor and inducing insulin-like effects $[1,2]$. Associated with obesity and regulated by cytokines known to promote insulin resistance, these observations indicate that visfatin may have a role in the pathogenesis of type II diabetes [3]. Current evidence for its role in the disease is mixed. Some studies suggest that visfatin is reduced in patients with type I diabetes, in individuals with type II diabetes who exercise regularly and in the $3^{\text {rd }}$ trimester of pregnancy where gestational diabetes is exhibited [4-7]. However, levels of visfatin have been reported to be elevated in the plasma of patients with type II diabetes [8], and a role for visfatin in the development of type II microvascular complications, for example diabetic nephropathy, cannot be ignored $[8,9]$.

Diabetic nephropathy is the single commonest cause of entry into the renal replacement therapy programme and with the incidence of the disease doubling in the past decade, diabetic nephropathy now accounts for approximately 50\% of patients presenting with end-stage renal failure $[10,11]$. Whilst our knowledge of a role for visfatin in mediating the underlying pathology of complications of type II diabetes is sparse, several reports confirm elevated visfatin in patient and animal models exhibiting diabetic nephropathy $[3,12]$, and increased levels of visfatin positively correlate to the degree of albuminuria in patients with type II diabetes, suggesting that endothelial dysfunction in early diabetic nephropathy may be linked to increased levels of this adipocytokine [8]. A number of studies have confirmed that the kidney is capable of synthesizing visfatin, a process exacerbated by high glucose [12]. Moreover, in mesangial cells and cells of the proximal tubule, visfatin promotes glucose influx and may be instrumental in the synthesis of pro-fibrotic molecules, including the beta1 isoform of Transforming Growth Factor (TGF- $\beta 1$ ), plasminogen activator inhibitor (PAI)1 and type I collagen [3]. Through these local paracrine effectors, these data suggest that visfatin may, in part, contribute to the underlying pathology of diabetic nephropathy.

Characterised by an accumulation of extracellular matrix (ECM) in both the glomerular mesangium and tubular interstitium, the diabetic kidney exhibits multiple structural and functional changes, which culminate in excessive fibrosis and renal scarring [13, 14]. These fibrotic changes represent the crucial pathology underlying progressive chronic kidney disease (CKD) in diabetes. Changes in expression of several epithelial cell recognition and organizational proteins are central to the progression of fibrosis, and a pivotal step is the loss of cell-adhesion associated with reduced expression of epithelial protein E-cadherin (ECAD) $[15,16]$. We have previously demonstrated that a loss in cell-cell adhesion is associated with a subsequent reduction in connexin expression [17]. Connexins (Cx) are membrane bound protein, which oligomerise into hexameric hemichannels (connexons) connecting the cytoplasm of adjoining cells and forming gap junctions. Gap-junctions (GJ) allow transfer of solutes, metabolic precursors and electrical currents [18], and are essential for synchronising activity to ensure appropriate function. To date our knowledge of a role for gap junctions in the kidney and in diabetic nephropathy is limited. Glucose decreases GJ-conductance and disrupts cellular homeostasis in a variety of cell systems $[19,20]$ and glucose-dependent down-regulation of $\mathrm{Cx} 43$ expression and GJ-communication has been reported in bovine retinal pericytes [21], endothelial [22], and epithelial cells [23]. Whilst the presence of GJs in the kidney has long been known, specific details regarding their function in the proximal tubule is sparse. Studies on renal vasculature have confirmed a role for various Cxs on renin secretion and the regulation of blood pressure [24], but minimal data exists on their role in tubular function where expression is also high. Using cells derived from the human proximal tubule, this study identifies a link between the adipocytokine visfatin, TGF- $\beta 1$ and reduced cell-to-cell coupling. These changes will have profound effects on overall tissue integrity and function and may represent key events orchestrating loss of function in diabetic nephropathy in patients with type II diabetes. 


\section{Materials and Methods}

Materials

Supplies for tissue culture were purchased from Invitrogen (Paisley, UK). Immobilon P membrane was from Millipore, Watford, UK and ECL from Amersham Biosciences, Buckinghamshire, UK. A Qproteome kit was obtained from Qiagen (Sussex, UK). Connexin antibodies were obtained from Santa Cruz (CA, USA). Anti-TGF- $\beta 1$ neutralising antibody was obtained from R\&D systems. Visfatin, TGF- $\beta 1$, Crystal violet, MTT and Lucifer Yellow and all other general chemicals were all obtained from Sigma (Poole, UK). Anti-TGF- $\beta 1$ ELISA was obtained from R\&D systems. LDH assay was obtained from Abcam.

Model cell line

HK2 cells were obtained from the ATCC Bio-resource Centre (LGC Standards. Middlesex, UK). Cells (passages 18-30) were maintained in DMEM/Hams F12 (DMEM/F12) medium (17.5mM glucose), supplemented with $10 \%$ fetal calf serum (FCS), glutamine $(2 \mathrm{mM})$, and EGF $(5 \mathrm{ng} / \mathrm{ml})$ and cultured at $37^{\circ} \mathrm{C}$ in a humidified atmosphere of $5 \% \mathrm{CO}_{2}$. Prior to treatment, cells were transferred to DMEM/F12 low glucose $(5 \mathrm{mM})$ for $48 \mathrm{hr}$ as described previously [25]. Cells were serum starved overnight before incubation with either visfatin $(10-200 \mathrm{ng} / \mathrm{mL})$, TGF- $\beta 1(2-10 \mathrm{ng} / \mathrm{mL}) \pm$ a TGF- $\beta 1$ specific neutralising antibody $(10 \mu \mathrm{g} / \mathrm{mL})$ for $48 \mathrm{hrs}$.

\section{MTT assay}

The 3-(4,5-Dimethylthiazol-2-yl)-2,5-diphenyltetrazolium bromide (MTT) assay is widely used for cytotoxicity assessments of pharmacological and chemical agents. Viable cells transport MTT into their mitochondria, the compound is then reduced to formazin (purple in color), and the latter is quantified colorometrically. The amount of color formed corresponds to the number of viable cells. HK2 cells were cultured in 96-well plates $\left(5 \times 10^{3}\right.$ cells/well) in $5 \mathrm{mM}$ glucose containing media for $48 \mathrm{hrs}$ prior to an overnight period of serum starvation. Cells were stimulated for $48 \mathrm{hrs}$ with visfatin $(10-200 \mathrm{ng} / \mathrm{mL})$ and proliferation analyzed using the MTT colorimetric assay (Roche) according to manufacturers instructions. The values were presented as a percentage of the MTT uptake that was observed in visfatin treated cells as compared to control cells.

Lactate Dehydrogenase Assay

Cell death or cytotoxicity is classically evaluated by the quantification of plasma membrane damage. Lactate dehydrogenase (LDH) is a stable enzyme, present in all cell types, and rapidly released into the cell culture medium upon damage of the plasma membrane. Therefore, LDH is a common marker used to determine cytotoxicity. HK2 cells were cultured in 96 -well plates $\left(5 \times 10^{3}\right.$ cells/well) in $5 \mathrm{mM}$ glucose containing media for $48 \mathrm{hrs}$ prior to an overnight period of serum starvation. Cells were stimulated for $48 \mathrm{hrs}$ with visfatin $(10-200 \mathrm{ng} / \mathrm{mL})$ and Lactate dehydrogenase levels assayed using the LDH-cytoxicity assay kit II (Abcam) according to manufacturers instructions. The values were presented as a percentage of the LDH release that was observed in visfatin treated cells as compared to control cells.

\section{Crystal Violet Assay}

This is a simple assay useful for obtaining quantitative information about the relative density of cells adhering to multi-well cluster dishes. Crystal Violet stains DNA and upon solubilization, the amount of dye taken up by the monolayer can be quantitated in a plate reader. HK2 cells were cultured in 96-well plates $\left(5 \times 10^{3}\right.$ cells/well) in $5 \mathrm{mM}$ glucose containing media for $48 \mathrm{hrs}$ prior to an overnight period of serum starvation. Cells were stimulated for $48 \mathrm{hrs}$ with visfatin $(10-200 \mathrm{ng} / \mathrm{mL})$ and cell density determined with crystal violet staining. Briefly, media was removed and cells were fixed for 10 mins with PFA. Following a brief wash with PBS, cells were incubated for $10 \mathrm{mins}$ at room temperature in a $1 \%$ Crystal Violet solution. After this time interval, all traces of dye were removed with distilled water and the stain solubilized with 1 $\%$ SDS. The values were presented as a percentage of cells staining in visfatin treated cells as compared to control cells.

\section{Quantification of TGF- $\beta 1$}

HK2 cells were cultured in $5 \mathrm{mM}$ glucose containing media for $48 \mathrm{hrs}$ prior to an overnight period of serum starvation. Cells were stimulated for $48 \mathrm{hrs}$ with visfatin $(10-200 \mathrm{ng} / \mathrm{mL})$ under serum-free 
conditions and total TGF- $\beta 1$ was measured by specific enzyme-linked immunosorbent assay (ELISA) of cell culture supernatant collected from growth-arrested HK2 cells. Active TGF- $\beta 1$ is measured directly and latent TGF- $\beta 1$ can be measured indirectly following acid activation of samples. This assay has $<1 \%$ crossreactivity for TGF- $\beta 2$ and TGF- $\beta 3$. TGF- $\beta 1$ concentration was normalized to $\mathrm{mg} / \mathrm{ml}$ of protein. Data were obtained as picograms of TGF- $\beta 1$ per milliliter per mg of protein.

\section{Immunoblotting}

Cytosolic proteins were prepared and separated by gel electrophoresis and electro-blotting onto Immobilon P membranes as described previously [26]. For determination of protein localization, proteins were harvested using the Qproteome cell compartment kit. Membranes were probed with specific polyclonal antibodies against anti-Cx26 (1:200), Cx43 (1:400) and Cx40 (1:500) (all Santa Cruz).

\section{Dye transfer}

Lucifer yellow was dissolved in $250 \mu \mathrm{l}$ of fresh $\mathrm{LiCl}$ (150mmol/l)/HEPES (10mmol/l; pH 7.2). Individual cells within a cell cluster were injected using an Injectman/Femtojet 5247 delivery system (Eppendorf, Hamburg, Germany). The duration of injection was set at $1 \mathrm{sec}$ with an injection pressure of 2psi and a compensation pressure of $0.7 \mathrm{psi}$. Dye transfer between coupled cells was recorded over $4 \mathrm{~min}$ using Metamorph software (Molecular Devices) and a Cool Snap HQ CCD camera (Roper Scientific).

\section{Electrophysiology}

Cell covered $16 \mathrm{~mm}$ glass cover-slips were transferred to the recording bath and perfused $(2 \mathrm{ml} / \mathrm{min})$ with physiological saline solution composed of (mM): $127 \mathrm{NaCl}, 1.9 \mathrm{KCl}, 1.2 \mathrm{KH}_{2} \mathrm{PO}_{4}, 26 \mathrm{NaHCO}_{3}, 1 \mathrm{MgCl}_{2}$, $2 \mathrm{CaCl}_{2}$ and $10 \mathrm{D}$-Glucose bubbled with $95 \% \mathrm{O}_{2} / 5 \% \mathrm{CO}_{2}$ and maintained at $32^{\circ} \mathrm{C}$. Cells were visualised (x600 magnification) using IR-DIC optics (Olympus BX51W1 microscope and Hitachi CCD camera). Paired whole cell patch-clamp recordings were made from neighbouring cells using thick-walled borosilicate (Harvard) glass pipettes (3-8M $\Omega$ ) containing (mM): 135 potassium gluconate, $7 \mathrm{NaCl}, 10 \mathrm{HEPES}, 0.5$ EGTA, 10 phosphocreatine, 2 MgATP, 0.3 NaGTP ( 300 mOSM, pH 7.2). Recordings were made using an Axon Multiclamp 700B amplifier (Molecular Devices) and digitized at $20 \mathrm{kHz}$ (Axon Digidata 1440a). Data acquisition and analysis was performed using pClamp (v10, Axon, Molecular Devices).

Following the establishment of paired whole cell recordings, the series resistance $(10-16 \mathrm{M} \Omega)$ was continually monitored and compensated appropriately. If the series resistance markedly changed during the recording, then the data was excluded from analysis. Coupling was detected by the observation of a membrane potential change in one cell following injection of hyperpolarising and depolarising current steps in the other cell. At the end of recordings, the electrodes were removed from the cells and identical current steps were injected to ensure that there was no cross talk between electrodes.

\section{Estimating Coupling Strength}

Input resistance and coupling coefficients (ratio of membrane potential changes between the two cells) were determined from membrane potential responses following the injection of a series of hyperpolarising and depolarising current steps into each cell. The junctional conductance $\left(G_{j}\right)$ was then calculated using the following equation $[27,28]$

$$
\mathrm{G}_{\mathrm{j} 12}=\mathrm{R}_{1} \mathrm{k}_{12} /\left(\left(\mathrm{R}_{1} \mathrm{R}_{2}\right)-\left(\mathrm{R}_{1} \mathrm{k}_{12}\right)^{2}\right)
$$

Where $R_{1}$ and $R_{2}$ are the input resistances of the 2 cells and $k_{12}$ is the coupling coefficient. Estimates were calculated in both directions between pairs of cells.

\section{Analysis}

Autoradiographs were quantified by densitometry using TotalLab 2003 (NonLinear Dynamics, Durham, NC USA). Where data was quantified, the non-stimulated, low glucose control condition was normalized to $100 \%$ and data from all other experimental conditions compared to this. Statistical analysis of data was performed using a one-way ANOVA test with a Tukey's multiple comparison post-test. Paired Patch data was analysed via $t$-test. Data are expressed as mean \pm SEM, and 'n' denotes the number of experiments. Probability $(P) *<0.05$ was taken to signify statistical significance. 


\section{Results}

The effect of Visfatin on cell viability and cytoxicity

Cells were cultured in $5 \mathrm{mM}$ glucose for $48 \mathrm{hrs}$ prior to being serum starved overnight. Cells were either non-stimulated (control) or stimulated for $48 \mathrm{hrs}$ with visfatin (10-200 ng/mL) under serum-free conditions and were assessed for cell viability by MTT uptake (uptake directly correlates with the number of viable cells). Incubation with visfatin at 10,100 and $200 \mathrm{ng} / \mathrm{mL}$ for $48 \mathrm{hrs}$ failed to significantly alter cell viability (Fig. $1 \mathrm{~A}, \mathrm{P}>0.05$, $\mathrm{n}=3$ ).

To confirm that the effects of visfatin, could not be attributable to toxicity at concentrations used in subsequent analysis, we used a crystal violet assay to measure the number of adherent cells after $48 \mathrm{hr}$ treatment with visfatin $(10-200 \mathrm{ng} / \mathrm{mL})$, in serumfree conditions. Cells were fixed and stained with crystal violet $(1 \% \mathrm{w} / \mathrm{v})$. The extent of dye uptake in visfatin treated cells did not significantly differ to that from control cells at 48hrs (Fig. 1B, P>0.05, n=3). Data from all 3 complimentary strategies was used to inform on the concentration of visfatin to be used in subsequent analysis, i.e. $10-200 \mathrm{ng} / \mathrm{mL}$.

As a complimentary strategy to assess membrane integrity, we used the Lactate Dehyrdogenase assay as a marker of LDH release from control versus visfatin-treated cells. Cells were stimulated for $48 \mathrm{hrs}$ with visfatin $(10-200 \mathrm{ng} / \mathrm{mL})$ under serum-free conditions prior to measuring LDH release. Results, expressed as a \% of LDH release as compared to control, indicate that there was no significant change in LDH release from cells treated with visfatin (Fig. 1C, $\mathrm{P}>0.05, \mathrm{n}=3$ ), suggesting that the adipocytokine $(10-200 \mathrm{ng} / \mathrm{mL})$ does not damage the cell membrane.

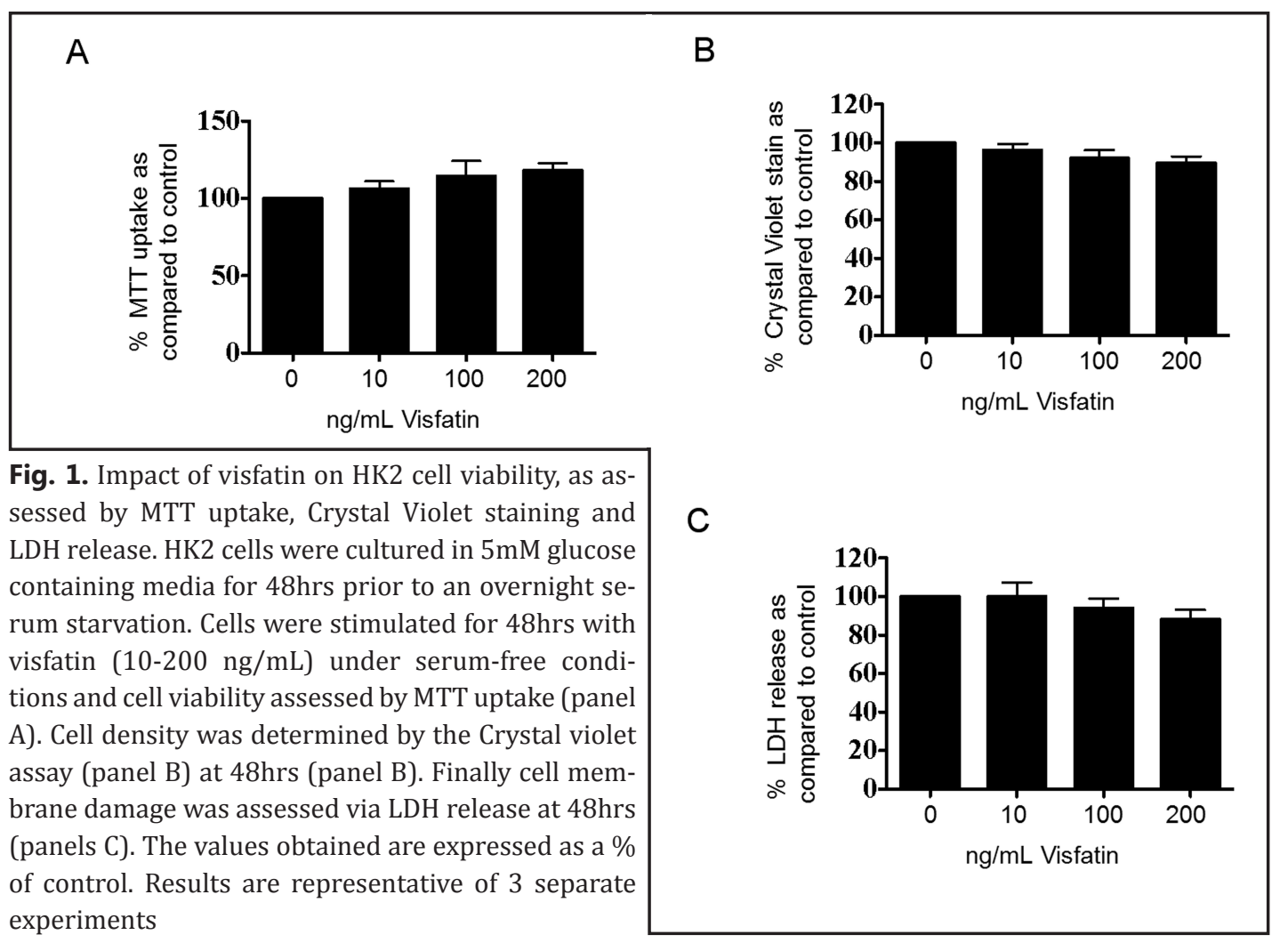




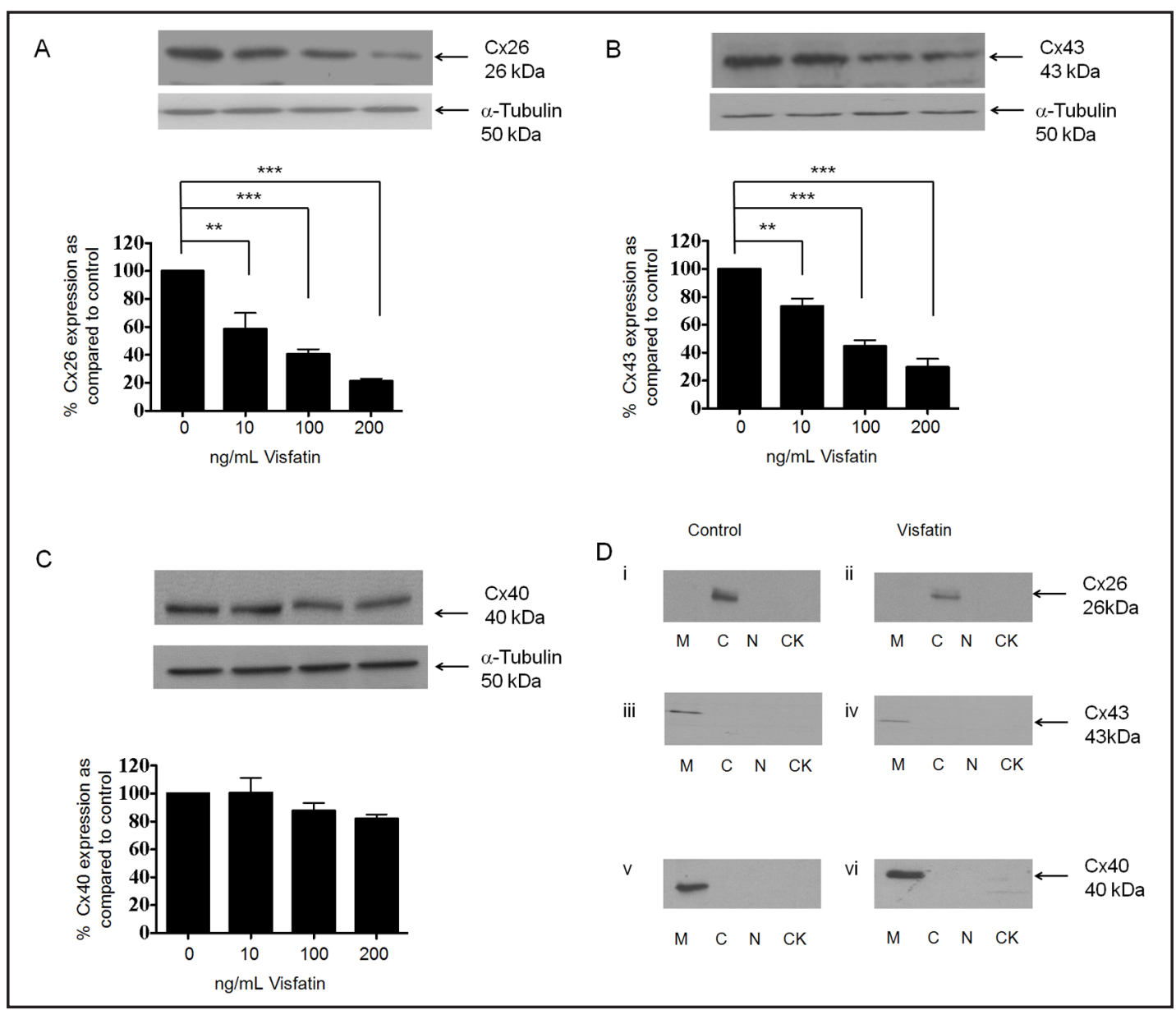

Fig. 2. Visfatin evoked changes in connexin expression in HK2-cells. To assess the effect of visfatin on expression of gap junction proteins HK2 cells were cultured in $5 \mathrm{mM}$ glucose containing media for $48 \mathrm{hrs}$ prior to overnight serum starvation. Cells were stimulated for $48 \mathrm{hrs}$ with visfatin (10-200 ng/mL) under serumfree conditions and phenotypic changes of $\mathrm{Cx} 26, \mathrm{Cx} 43$ and $\mathrm{Cx} 40$ assessed. Whole cell expression was determined by western blotting and confirmed that Visfatin evoked a dose dependent decrease in expression of both Cx26 (panel A) and Cx43 (panel B). Compartmental localisation of Cx26 and Cx43 were determined for membrane (M), cytosol (C), nuclear (N) and cytoskeletal (CK) fractions +/-Visfatin (200ng/mL). Visfatin altered the cellular localization of both $\mathrm{Cx} 26$ and $\mathrm{Cx} 43$ as compared to control (panels Dii, and Div respectively). However, visfatin failed to exert a significant effect over expression and cell localisation of $\mathrm{Cx} 40$ (panel C and Dvi respectively). Upper panels show representative blots for each protein and re-probed for $\alpha$-tubulin as a loading control. Lower panels show mean $( \pm$ SEM) densitometry data, normalised against the non-stimulated low glucose control (100\%), from 3 or more separate experiments. Each lane in the representative blot corresponds to the associated bar in the graph. Key significances are shown, ${ }^{* *} P<0.01$, $* * * P<0.001$.

Visfatin evokes a concentration-dependent down-regulation of Cx26 and Cx43 in HK2 cells HK2 cells were cultured in $5 \mathrm{mM}$ glucose prior to overnight serum starvation. Cells were then stimulated for $48 \mathrm{hrs}$ with visfatin $(10-200 \mathrm{ng} / \mathrm{mL})$ under serum-free conditions and cell lyastes analysed by immunoblotting to determine the effects of the adipocytokine on the expression of $\mathrm{Cx} 26, \mathrm{Cx} 40$ and $\mathrm{Cx} 43$. Visfatin decreased whole-cell expression of $\mathrm{Cx} 26$ in a concentration-dependent manner to $58 \pm 11 \%, 40 \pm 3 \%$ and $21 \pm 2 \%$ as compared to control at 10,100 and $200 \mathrm{ng} / \mathrm{mL}$ respectively (Fig. $2 \mathrm{~A} \mathrm{n}=3 ; P<0.01$ ). Cell compartment analysis revealed that the loss in Cx26 expression was attributable to a decrease in expression from both the cell membrane and cytosol (Fig. 2Di and ii). Similarly, visfatin also decreased Cx43 
Fig. 3. Visfatin stimulates TGF- $\beta 1$ secretion in HK2 cells. HK2 cells were cultured in $5 \mathrm{mM}$ glucose containing media for $48 \mathrm{hrs}$ prior to overnight serum starvation. Cells were stimulated for $48 \mathrm{hrs}$ with visfatin $(10-200 \mathrm{ng} / \mathrm{mL})$ under serum-free conditions. The supernatant was removed and TGF- $\beta 1$ secretion (pg/mL) as compared to control. Results are representative of 3 separate experiments. Key significances are shown where ${ }^{*} P<0.05$.

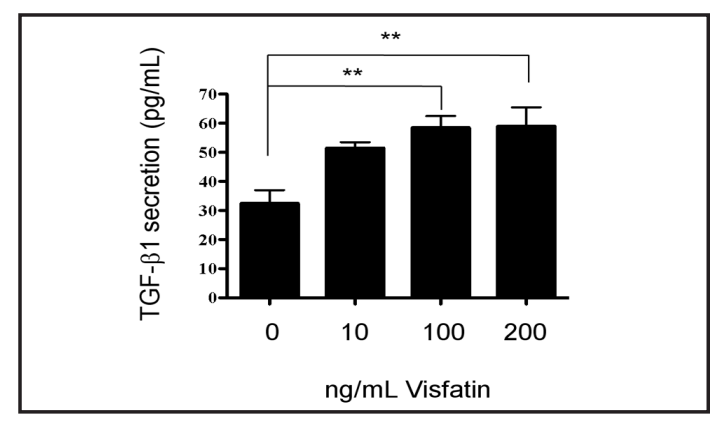

to $73 \pm 5 \%, 44 \pm 4 \%$ and $29 \pm 6 \%$ as compared to control at 10,100 and $200 \mathrm{ng} / \mathrm{mL}$ respectively (Fig. $2 \mathrm{~B} \mathrm{n}=3 ; P<0.01$ ). Cell compartment anaylsis revealed that this loss appeared attributable to a reduction in $\mathrm{Cx} 43$ from the cell membrane (Fig. 2Diii and iv). Not all connexin isoforms respond to visfatin and the adiopocytokine failed to alter $\mathrm{Cx} 40$ expression (Fig. 2C) which was predominantly localised to the membrane region of the cell (Fig. 2Dv and vi).

Visfatin increases secretion of TGF- $\beta 1$

The pro-fibrotic cytokine TGF- $\beta 1$ is a principal mediator of fibrotic changes in the kidney. TGF- $\beta 1$ modulates the expression of several epithelial cell recognition and organizational proteins, whilst contributing to the reciprocal loss of tubular epithelial cells and accumulation of interstitial fibroblasts, changes associated with declining excretory function $[14,29,30]$. To determine if visfatin stimulated TGF- $\beta 1$ secretion, cells were cultured in $5 \mathrm{mM}$ glucose prior to being starved of serum overnight. Cells were stimulated for $48 \mathrm{hrs}$ with visfatin (10$200 \mathrm{ng} / \mathrm{mL}$ ) under serum-free conditions and a TGF- $\beta 1$ ELISA was used to measure total secretion from growth-arrested HK2 cells. ELISA of supernatant showed that exposure of HK2 cells to visfatin for $48 \mathrm{hrs}$ evoked a rise in total TGF- $\beta 1$ secretion to $51 \pm 4 \mathrm{pg} / \mathrm{mL}$, $58 \pm 6 \mathrm{pg} / \mathrm{mL}$ and $59 \pm 10 \mathrm{pg} / \mathrm{mL}$ respectively at 10,100 and $200 \mathrm{ng} / \mathrm{mL}$ visfatin (Fig. 3 ), as compared to a $5 \mathrm{mM}$ glucose control; $32 \pm 7 \mathrm{pg} / \mathrm{mL}(n=3 ; P<0.01)$. Differences in TGF- $\beta 1$ were only detected following acidification of the samples, suggesting that TGF- $\beta 1$ was produced in its latent form.

\section{TGF- $\beta 1$ down-regulates $C \times 26$ and $C x 43$}

Having confirmed that visfatin down-regulates $\mathrm{Cx} 26$ and $\mathrm{Cx} 43$ expression and increases secretion of TGF- $\beta 1$ we wanted to determine the effects of TGF- $\beta 1$ on $\mathrm{Cx} 26, \mathrm{Cx} 43$ and $\mathrm{Cx} 40$ expression to see if the effects of the pro-fibrotic cytokine matched those of visfatin. HK2 cells were cultured in $5 \mathrm{mM}$ glucose prior to overnight serum starvation. Cells were then stimulated for $48 \mathrm{hrs}$ with TGF- $\beta 1(2-10 \mathrm{ng} / \mathrm{mL})$ under serum-free conditions. TGF- $\beta 1$ decreased whole-cell expression of $\mathrm{Cx} 26$ in a concentration-dependent manner to $37 \pm 24 \%$, $22 \pm 5 \%$ and $15 \pm 8 \%$ as compared to control at 2,4 and $10 \mathrm{ng} / \mathrm{ml}$ respectively (Fig. $4 \mathrm{~A} \mathrm{n}=3$; $P<0.001)$. Cell compartment analysis revealed that this loss in expression was attributable to removal of Cx26 from the cytosol (Fig. 4Di and ii). Similarly, TGF- $\beta 1$ also reduced Cx43 expression with expression falling to $52 \pm 15 \%, 28 \pm 9 \%$ and $9 \pm 18 \%$ as compared to control at 2,4 and $10 \mathrm{ng} / \mathrm{ml}$ respectively (Fig. $4 \mathrm{~B} \mathrm{n}=3 ; P<0.001$ ). The loss of whole cell expression was primarily attributable to removal of $\mathrm{Cx} 43$ from the cell membrane (Fig. 4Diii and iv). In support of our previous data for visfatin, TGF- $\beta 1$ failed to alter Cx40 expression (Fig 4C), which remained predominantly located at the membrane (Fig. 4Dv and vi).

Visfatin evoked changes in CX26 and CX43 expression are mediated by TGF- $\beta 1$

To determine the role of TGF- $\beta 1$ in mediating the visfatin-evoked loss in Cx26 and Cx43 expression we examined the effect of visfatin $(200 \mathrm{ng} / \mathrm{mL})$ in conjunction with a TGF- $\beta 1$ specific immunoneutralising antibody (Fig. $5 \mathrm{~A}$ and B respectively). HK2 cells were cultured in $5 \mathrm{mM}$ glucose prior to overnight serum starvation. Cells were then stimulated for $48 \mathrm{hrs}$ with visfatin $(200 \mathrm{ng} / \mathrm{mL})+/$ - a TGF- $\beta 1$ specific immunoneutralising antibody $(10 \mu \mathrm{g} / \mathrm{mL})$ 


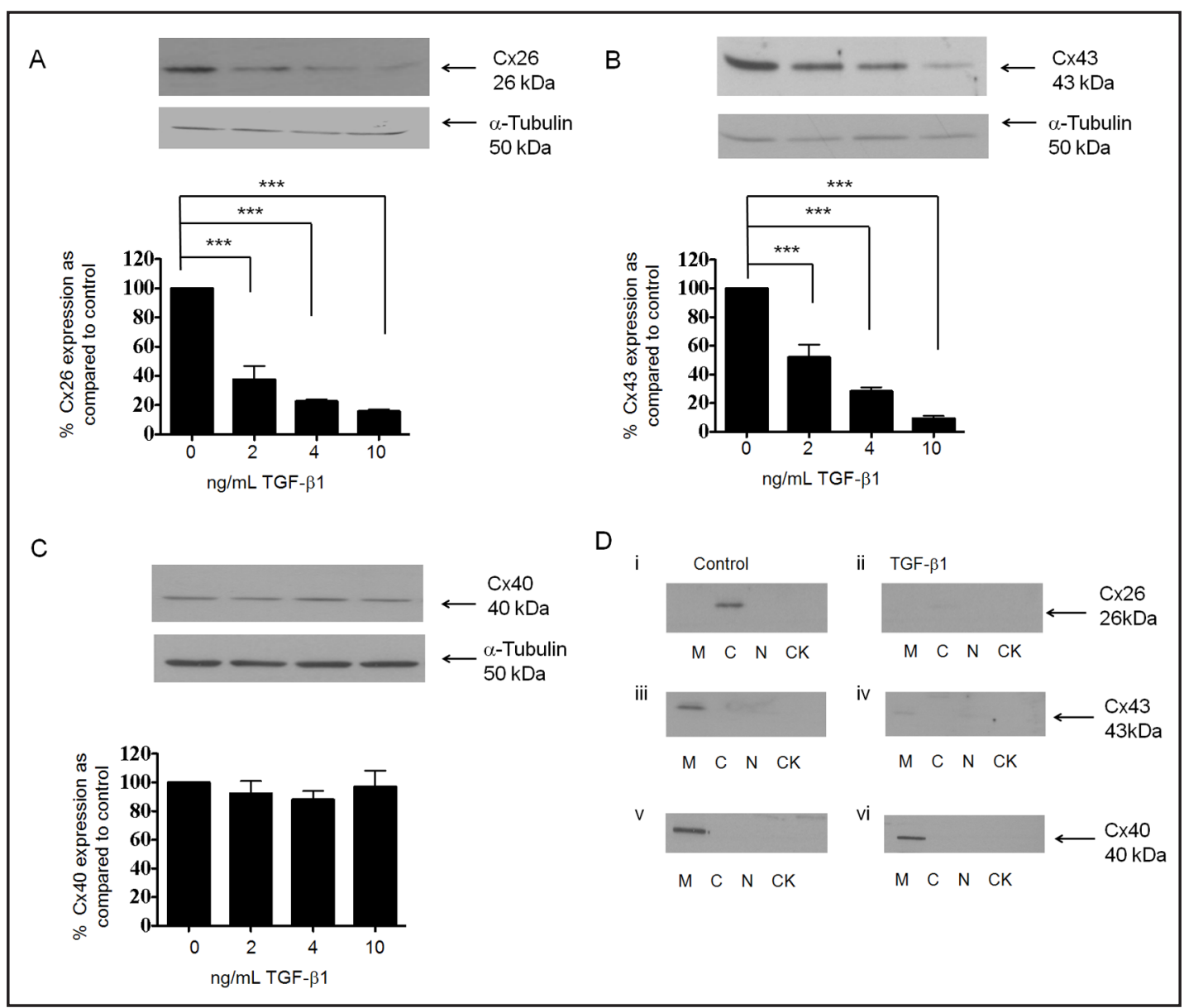

Fig. 4. TGF- $\beta 1$ evoked changes in connexin expression in HK2-cells. To assess the effect of TGF- $\beta 1$ on expression of gap junction proteins, HK2 cells were cultured in $5 \mathrm{mM}$ glucose containing media for $48 \mathrm{hrs}$ prior to overnight serum starvation. Cells were stimulated for $48 \mathrm{hrs}$ with TGF- $\beta 1(2-10 \mathrm{ng} / \mathrm{mL})$ under serum-free conditions and phenotypic changes of $\mathrm{Cx} 26, \mathrm{Cx} 43$ and $\mathrm{Cx} 40$ assessed. Whole cell expression was determined by western blotting and confirmed that visfatin evoked a dose dependent decrease in expression of both Cx26 (panel A) and Cx43 (panel B). Compartmental localisation of Cx26 and Cx43 were determined for membrane (M), cytosol (C), nuclear (N) and cytoskeletal (CK) fractions + /- TGF- $\beta 1$ (2-10ng/ $\mathrm{mL}$ ). TGF- $\beta 1$ altered the cellular localization of both $\mathrm{Cx} 26$ and $\mathrm{Cx} 43$ as compared to control (panels Dii, and Div respectively). However, TGF- $\beta 1$ failed to exert a significant effect over expression and cell localisation of Cx40 (panel C and Dvi respectively). Upper panels show representative blots for each protein and reprobed for $\beta$-tubulin as a loading control. Lower panels show mean $( \pm \mathrm{SEM})$ densitometry data, normalised against the non-stimulated low glucose control (100\%), from 3 or more separate experiments. Each lane in the representative blot corresponds to the associated bar in the graph. Key significances are shown, $* * * P<0.001$.

under serum-free conditions. Cell lysates were analysed by immunoblotting to determine the effects of the adipocytokine on the expression of Cx26 and Cx43. As previously observed, Visfatin (200ng/mL) decreased whole-cell expression of Cx26 to 32 $215 \%$, as compared to control $(n=3, P<0.001)$ (Fig. 5A). However, co-incubation with TGF- $\beta 1$-specific immunoneutralising antibody negated the effect of visfatin, with Cx26 expression remaining at $90 \pm 6 \%$; as compared to low glucose (5mM) control. Visfatin (200ng/mL) decreased Cx43 expression to $27 \pm 18 \%$, as compared to control $(\mathrm{n}=3, \mathrm{P}<0.001)$ (Fig. 5B). Co-incubation with a TGF- $\beta 1$-specific immuno-neutralising antibody negated the effect, with $\mathrm{Cx} 43$ expression remaining at $81 \pm 4 \%$; as compared to low glucose $(5 \mathrm{mM})$ control. Incubation with TGF- $\beta 1$ specific immuno-neutralising antibody had no effect on Cx26 or Cx43 expression. 


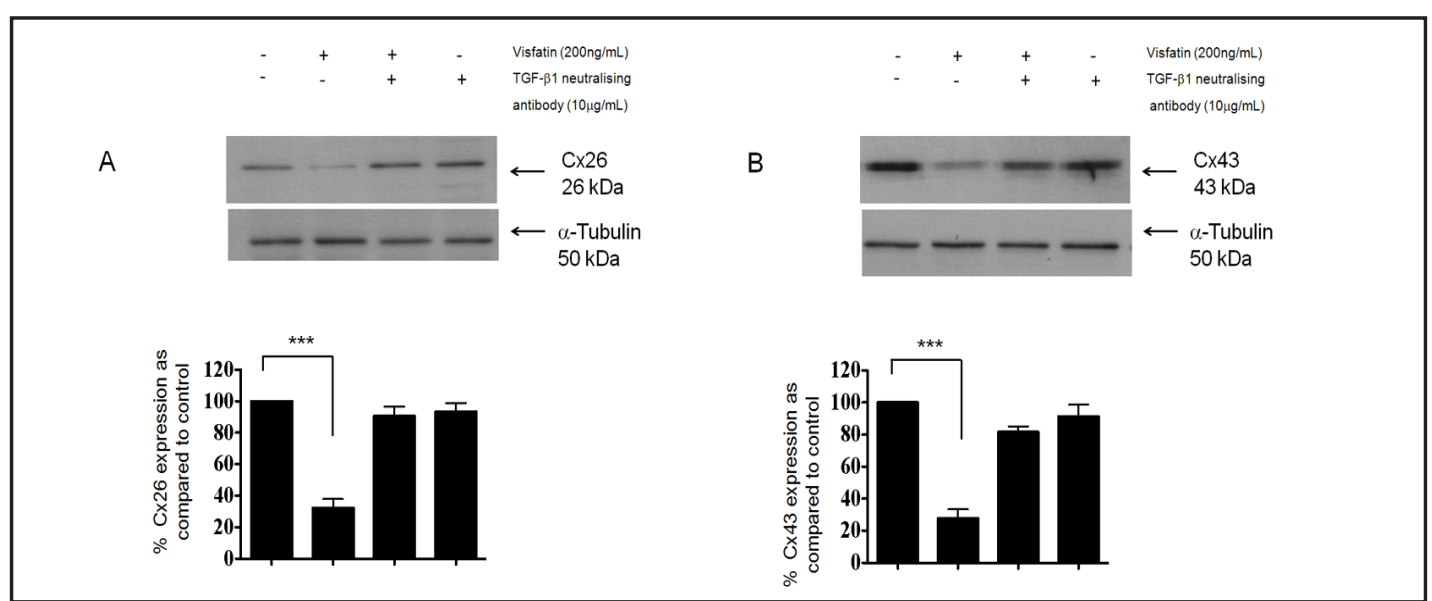

Fig. 5. Visfatin evoked changes in connexin expression in HK2-cells are mediated by TGF- $\beta 1$. To determine if the effects of visfatin on expression of gap junction proteins are mediated by downstream TGF- $\beta 1$, cells were cultured in $5 \mathrm{mM}$ glucose for $48 \mathrm{hrs}$ prior to being serum starved overnight. Cell were then stimulated for $48 \mathrm{hrs}$ with either visfatin $(200 \mathrm{ng} / \mathrm{mL})+/$ - TGF- $\beta 1$ neutralising antibody $(10 \mu \mathrm{g} / \mathrm{mL})$, or TGF- $\beta 1$ neutralising antibody $(10 \mu \mathrm{g} / \mathrm{mL})$ alone, under serum-free conditions. Whole cell expression of Cx26 and Cx43 was determined by western blotting and confirmed that the adipocytokine decreased expression of both Cx26 (Panel A) and Cx43 (Panel B). The effect was negated by neutralising TGF- $\beta 1$. Upper panels show representative blots for each protein and re-probed for $\beta$-tubulin as a loading control. Lower panels show mean $( \pm$ SEM) densitometry data, normalised against the non-stimulated low glucose control $(100 \%)$, from 3 or more separate experiments. Each lane in the representative blot corresponds to the associated bar in the graph. Key significances are shown, ${ }^{* * *} P<0.01$.

Visfatin-induced loss in Cx-expression is associated with impaired cell-coupling

To determine if visfatin-evoked loss in Cx-expression had functional implications for cell-to-cell communication we examined changes in dye-transfer and junctional conductance between HK2 cells using paired-patch recording. Cells were seeded onto coverslips and cultured in $5 \mathrm{mM}$ glucose prior to being starved of serum overnight. Cells were stimulated for $48 \mathrm{hrs}$ with visfatin $(10-200 \mathrm{ng} / \mathrm{mL})$ under serum-free conditions and gap junction intercellular communication (GJIC) assessed (Fig. 6).

Lucifer yellow is a membrane impermeant dye, which moves between adjacent cells via gap junctions. The dye was injected into individual cells within a cell cluster (5-8 cells/ cluster). Cells treated for $48 \mathrm{hrs}$ with either TGF- $\beta 1(2-10 \mathrm{ng} / \mathrm{mL})$ or visfatin $(10-200 \mathrm{ng} /$ $\mathrm{mL}$ ) failed to exhibit dye transfer (Fig. 6B and $\mathrm{C}$ respectively), whilst dye injected into nonstimulated control cells propagated away from the site of injection into neighbouring cells, suggesting gap junction-mediated intercellular communication (Fig. 6A). Incubation of cells with visfatin $(200 \mathrm{ng} / \mathrm{mL})$, in the presence of a TGF- $\beta 1$ neutralising antibody $(10 \mu \mathrm{g} / \mathrm{mL})$, permitted dye transfer into neighbouring cells and away from the site of injection, suggesting that the loss of gap junction-mediated intercellular communication in response to visfatin is TGF- $\beta 1$ dependent (Fig. 6D).

Paired whole cell patch clamp recordings were used to determine both the junctional conductance and the input resistance of HK2 cells \pm visfatin $(200 \mathrm{ng} / \mathrm{mL})$. Cells were seeded onto coverslips and cultured in $5 \mathrm{mM}$ glucose prior to starvation overnight without serum. Cells were stimulated for $48 \mathrm{hrs}$ with visfatin $(200 \mathrm{ng} / \mathrm{mL})$. Representative recordings are illustrated for control (Fig. 6 Ei and F) and visfatin treated cells (Fig. 6 Eii and G). Input resistance was calculated from the slope of the current-voltage relationship around the resting potential of the cells. Under control conditions (Fig. 6 Ei) the resistance of cell 1 was $154 \mathrm{M} \Omega$, and the resistance for cell 2 was $256 \mathrm{M} \Omega$, the coupling coefficient was 0.48 , giving a junctional conductance of $2.19 \mathrm{nS}$. In cells treated with visfatin (200ng/mL) (Fig. 6Eii) the resistance of cell 1 was $395 \mathrm{M} \Omega$ and the resistance of cell 2 was $163 \mathrm{M} \Omega$, the coupling coefficient was 0.10 , giving a junctional conductance of $0.61 \mathrm{nS}$. 


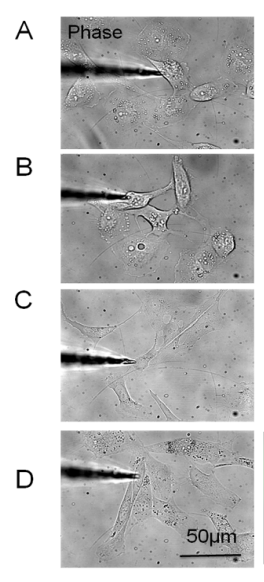

E

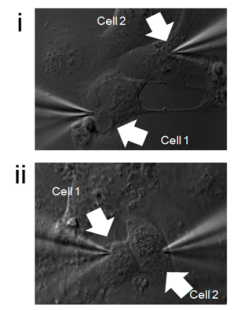

$\mathrm{H}$
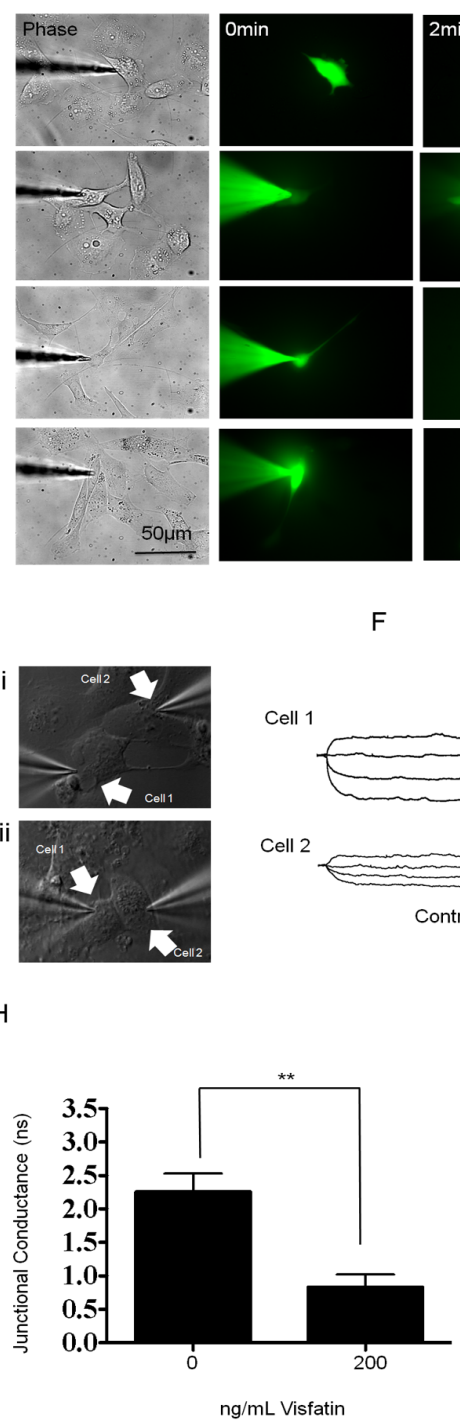

$\mathrm{F}$

Cell 1

Cell 2
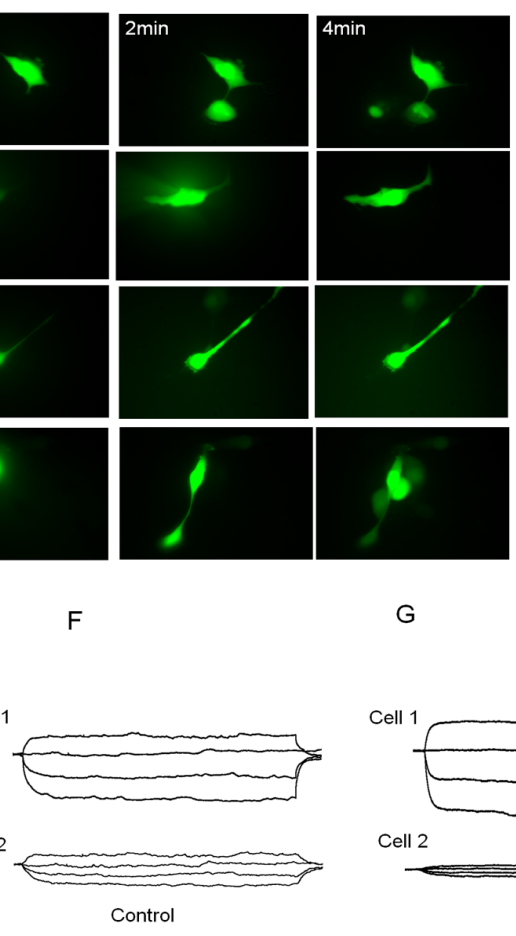

G

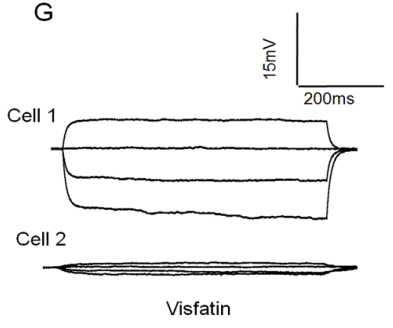

I

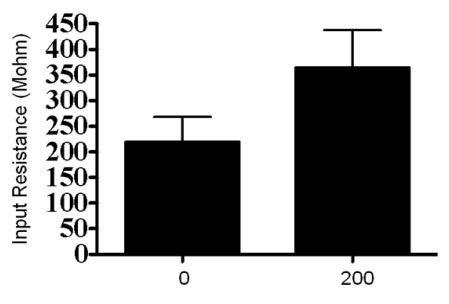

$\mathrm{ng} / \mathrm{mL}$ Visfatin

Fig. 6. Visfatin-induced loss in Cx-expression is associated with impaired cell-coupling in HK2 cells. Panels A-D show Lucifer yellow dye transfer between HK2-cells. Monochrome plates illustrate phase images of HK2-cell clusters. Fluorescence (fluorescein) image of same cell clusters after single-cell injection with Lucifer yellow is shown at time 0 . The same field of view is recorded 2 and 4 min after injection of dye in control cells (A), in the presence of TGF- $\beta 1(10 \mathrm{ng} / \mathrm{mL} ; \mathrm{B})$, in cells treated with visfatin $(200 \mathrm{ng} / \mathrm{mL} ; \mathrm{C})$ and lastly in cells treated with visfatin $(200 \mathrm{ng} / \mathrm{mL})+$ TGF- $\beta 1$ neutralising antibody $(10 \mu \mathrm{g} / \mathrm{mL}$; D). The transfer of dye supports direct cell-to-cell communication between coupled cells and is only seen in control cells or following neutralization of TGF- $\beta 1$ with visfatin. Panel E, show the positioning of electrodes (arrows) for paired whole cell patch clamp recordings from cells in a control culture (i) and in a culture treated with visfatin (ii). The electrophysiological data for these paired recordings is illustrated in (F, control) and (G, visfatin treated). F, Hyperpolarising and depolarising current steps (40 pA) injected into cell-1 produced voltage responses in cell-2 demonstrating that the cells are electrically coupled. The junctional conductance was calculated as $2.19 \mathrm{nS}$. F, Hyperpolarising and depolarising current steps (20 pA) injected into cell-1 produced voltage responses in cell-2 demonstrating that they are electrically coupled. The junctional conductance was calculated as $0.61 \mathrm{nS}$. Panel H, Graph plotting the mean junctional conductance for pairs of cells in control conditions versus cells treated with visfatin. The junctional conductance is significantly reduced in visfatin (2-tailed unpaired t-test, $P<0.01$ ). Panel $\mathrm{I}$, shows mean input resistance for cells in control and treated with visfatin. Although there is a trend towards an increase in input resistance this is not significant (as there is a large variation in input resistance across cells). 
The junctional conductance in HK2 cells in control conditions was $2.25 \pm 0.2 \mathrm{nS}(n=6)$. Treatment with visfatin significantly reduced the junctional conductance $63 \%$ reduction to $0.83 \pm 0.19 \mathrm{nS}$ Fig. $6 \mathrm{H} \mathrm{n}=6 ; P<0.01$ ). The fall in junctional conductance would be expected to increase the input resistance of the cells as less current will leak out of the membrane. (Fig. $6 I)$.

\section{Discussion}

Produced and secreted mainly by visceral adipose tissue, adipocytokines have been studied for their association with insulin resistance and metabolic syndrome [1,2]. Elevated in patients with type II diabetes and linked to endothelial dysfunction, a series of studies have addressed the potential role of visfatin in the pre-disposition of micro-vascular complications $[3,8,9]$. The current study suggests that visfatin can modulate gap junction mediated cell-to-cell communication in the human proximal tubule, a process that may have implications for renal function ahead of overt changes that are central to the progression of renal fibrosis. We have demonstrated that cells of the human proximal tubule express the gap junction proteins $\mathrm{Cx} 26, \mathrm{Cx} 40$ and $\mathrm{Cx} 43$ and that the expression of $\mathrm{Cx} 26$ and $\mathrm{Cx} 43$ are sensitive to increased levels of the adipocytokine. A loss in Cx-expression may be crucial in the development of complications of diabetes. In retinal capillaries of diabetic mice, $\mathrm{Cx} 43$ expression is reduced and apoptosis increased, resulting in a loss of cell-cell communication and a decline in the number of pericytes and acellular capillaries [19]. Similar findings in vascular endothelial cells, confirm that high glucose decreases Cx-expression/function and that this is an early trigger for apoptosis [20]. The data highlight the importance of GJ-mediated cell-to-cell coupling and suggests that a loss in cell-cell communication may contribute to some micro-vascular complications associated with diabetes.

More than a dozen fibrogenic factors affect renal function, however, it is widely recognised that the pro-fibrotic cytokine TGF- $\beta 1$ and its downstream signalling partners represents the predominant pathway orchestrating renal fibrosis $[15,16]$. In the current study we confirm that visfatin evokes an increase in TGF- $\beta 1$ secretion in and that exogenous application of TGF- $\beta 1$ to HK2 cells induces synonymous effects to visfatin in reducing both Cx26 and Cx43 expression. Furthermore, using a TGF- $\beta 1$ specific neutralising antibody, we confirm that the effects of visfatin are, at least in part, mediated by TGF- $\beta 1$. Abnormalities in TGF- $\beta 1$ have been linked to a variety of disorders, including autoimmune diseases, malignancies, and chronic renal disease [11]. TGF $\beta 1$ is important in many tubulointerstitial diseases where disassembly of the adherens junction represents the initial overt change in epithelial organisation, well before any suggested cellular migration associated with epithelial-to-mesenchymal transition (EMT), a process in which cells convert from an epithelial to mesenchymal phenotype, and an event central to the progression of tubulointerstitial fibrosis. $[15,16]$. In the current study, we have used dye transfer and paired patch clamp recordings to provide functional evidence that visfatin dramatically reduces connexin mediated intercellular communication in the proximal tubule, an effect that may be associated with the early renal damage in type II diabetes.

In podocytes and cells of the proximal tubule, that are able to synthesize visfatin, GLUT1-dependent glucose uptake is increased [3]. In 2010, Kang et al. confirmed that the concentration of visfatin in both the glomeruli and tubulointerstitium, was increased in a rodent model of type II diabetes mellitus [3]. Since then, elevated levels of circulating visfatin have been found in patients with the disease [31]. Plasma visfatin levels are significantly elevated in early stages of diabetic nephropathy and positively correlate with body weight, fasting plasma glucose and microalbuminuria $[3,9]$. The current study demonstrates that when the concentration of this important adipocytokine increases, gap-junction mediated intercellular communication between cells of the proximal tubule decreases. Our data could help explain an early loss in renal function in patients with T2DM. 
Hills/Kerr/Wall/Squires: Visfatin and Cell Communication

\section{Conflict of Interest}

The authors declare that there is no duality of interest associated with this manuscript.

\section{Acknowledgements}

This work was supported wholly or in part by the generous support of Diabetes UK (BDA: 11/0004215), and The Warwickshire Private Hospital (WPH) Charitable Trust.

\section{References}

1 Samal B, Sun Y, Stearns G, Xie C, Suggs S, McNiece I: Cloning and characterization of the cDNA encoding a novel human pre-B-cell colony-enhancing factor. Mol Cell Biol 1994;2:1431-1437.

2 Jia SH, Li Y, Parodo J, Kapus A, Fan L, Rotstein OD, Marshall JC: Pre-B cell colony-enhancing factor inhibits neutrophil apoptosis in experimental inflammation and clinical sepsis. J Clin Invest 2004;113:1318-1327.

- 3 Kang YS, Song HK, Lee MH, Ko GJ, Han JY, Han SY, Han KH, Kim HK, Cha DR: Visfatin is upregulated in type-2 diabetic rats and targets renal cells. Kidney Int 2010;78:170-181.

-4 Toruner F, Altinova AE, Bukan N, Arslan E, Akbay E, Ersoy R: Plasma visfatin concentrations in subjects with type 1 diabetes mellitus. Horm Res 2009;72:33-37.

-5 Akturk M, Altinova AE, Mert I, Buyukkagnici U, Sargin A, Arslan M: Visfatin concentration is decreased in women with gestational diabetes mellitus in the third trimester. J Endocrinol Invest 2008;31:610-613.

6 Brema I, Hatunic M, Finucane F, Burns N, Nolan JJ, Haider D: Plasma visfatin is reduced after aerobic exercise in early onset type 2 diabetes mellitus. Diabetes Obes Metab 2008;10:600-602.

$\checkmark 7$ Chan TF, Chen YL, Lee CH, Chou FH, Wu LC, Jong SB: Decreased plasma visfatin concentrations in women with gestational diabetes mellitus. J Soc Gynecol Investig 2006; 13:364-367.

-8 Yilmaz MI, Saglam M, Qureshi AR, Carrero JJ, Caglar K, Eyileten T: Endothelial dysfunction in type-2 diabetics with early diabetic nephropathy is associated with low circulating adiponectin. Nephrol Dial Transplant 2008; 23:1621-1627.

-9 Song HK, Lee MH, Kim BK, Park YG, Ko GJ, Kang YS, Han JY, Han SY, Han KH, Kim HK, Cha DR: Visfatin: a new player in mesangial cell physiology and diabetic nephropathy. Am J Physiol Renal Physiol 2008;295:F14851494.

10 Kanwar YS, Wada J, Sun L: Diabetic nephropathy: mechanisms of renal disease progression. Exp Biol Med 2008:233:4-11.

11 Sharma K and Ziyadeh FN: Hyperglycaemia and diabetic kidney disease. The case for transforming growth factor-beta as a key mediator. Diabetes 1995;44:1139-1146.

12 Saddi-Rosa P, C Oliveira CSV, Giuffrida FMA, Reis AF: Visfatin, glucose metabolism and vascular disease: a review of evidence. Diabetol Metab Syndr 2010;2:21 doi:10.1186/1758-5996-2-21.

13 Remuzzi G, Ruggenenti P, Benigni A: Understanding the nature of renal disease progression. Kidney Int 1997;51:2-15.

-14 Eddy AA: Molecular insights into renal interstitial fibrosis. J Am Soc Nephrol 1996;12:2495-2508.

15 Hills CE, Squires PE: TGF-beta1-induced epithelial-to-mesenchymal transition and therapeutic intervention in diabetic nephropathy. Am J Nephrol 2010;31:68-74.

16 Hills CE, Squires PE: The role of TGF- $\beta$ and epithelial-to mesenchymal transition in diabetic nephropathy. Cytokine Growth Factor Rev 2011;22:131-139.

17 Hills CE, Siamantouras E, Smith SW, Cockwell P, Liu KK, Squires PE: TGF $\beta$ modulates cell-to-cell communication in early epithelial-to-mesenchymal transition. Diabetologia 2012;55:812-824.

18 Caton D, Calabrese A, Mas C, Serre-Beinier V, Wonkam A, Meda P: Beta-cell crosstalk: a further dimension in the stimulus-secretion coupling of glucose-induced insulin release. Diabetes Metab 2002;28:3S45-53.

19 Bobbie MW, Roy S, Trudeau K, Munger SJ, Simon AM, Roy S: Reduced connexin 43 expression and its effect on the development of vascular lesions in retinas of diabetic mice. Invest Opthalmol Vis Sci 2001;51:37583763. 
20 Li AF, Roy S: High glucose induced downregulation of connexin 43 expression promotes apoptosis in microvascular endothelial cells. Invest Opthalmol Vis Sci 2009;50:1400-1407.

21 Facemire CS, Gurley SB: Minding the gap: connexin 40 at the heart of renin release. J Am Soc Nephrol 2011;22:985-986.

22 Sato T, Haimovici R, Kao R, Li AF, Roy S: Downregulation of connexin 43 expression by high glucose reduces gap junction activity in microvascular endothelial cells. Diabetes 2002;51:1565-1571.

-23 Fernandes R, Girão H, Pereira P: High glucose down-regulates intercellular communication in retinal endothelial cells by enhancing degradation of connexin 43 by a proteasome-dependent mechanism. J Biol Chem 2004;279:27219-27224.

-24 Hanner F, Sorensen CM, Holstein-Rathlou NH, Peti-Peterdi J: Connexins and the kidney. Am J Physiol Regul Integr Comp Physiol 2010;298:R1143-1155.

25 Hills CE, Bland R, Bennett J, Ronco PM, Squires PE: TGF-beta1 mediates glucose-evoked up-regulation of connexin-43 cell-to-cell communication in HCD-cells. Cell Physiol Biochem 2009;24:177-186.

26 Hills CE, Bland R, Bennett J, Ronco PM, Squires PE: High glucose up-regulates ENaC and SGK1 expression in HCD-cells. Cell Physiol Biochem 2006;18:337-346.

27 Bennett MVL: Physiology of electrotonic junctions. Ann N Y Acad Sci 1966;137:509-539.

28 Nolan MF, Logan SD, Spanswick D: Electrophysiological properties of electrical synapses between rat sympathetic preganglionic neurones in vitro. J Physiol 1999;519:753-764.

29 Hills CE, Willars GB, Brunskill NJ: Proinsulin C-peptide antagonizes the profibrotic effects of TGF-beta1 via up-regulation of retinoic acid and HGF-related signaling pathways. Mol Endocrinol 2010;24:822-831.

-30 Hills CE, Al-Rasheed N, Al-Rasheed N, Willars GB, Brunskill NJ: C-peptide reverses TGF-beta-1 induced changes in renal proximal tubular cells: implications for treatment of DN. Am J Physiol 2009;296:F614-621.

-31 McGee KC, Harte AL, da Silva NF, Al-Daghri N, Creely SJ, Kusminski CM, Tripathi G, Levick PL, Khanolkar M, Evans M, Chittari MV, Patel V, Kumar S, McTernan PG: Visfatin is regulated by rosiglitazone in type 2 diabetes mellitus and influenced by NFKB and JNK in human abdominal subcutaneous adipocytes. PLoS ONE 2011;6:e20287. doi:10.1371/journal.pone.0020287. 